\title{
The PTEN/PI3K/AKT pathway in vivo, cancer mouse models
}

\author{
Amancio Carnero $^{1 *}$ and Jesus M. Paramio ${ }^{2,3}$ \\ 1 Instituto de Biomedicina de Sevilla (IBiS), Hospital Universitario Virgen del Rocio/CSIC/Universidad de Sevilla, Seville, Spain \\ ${ }^{2}$ Molecular Oncology Unit, Division of Biomedicine, CIEMAT, Madrid, Spain \\ ${ }^{3}$ Oncogenomics Unit, Biomedical Research Institute, "12 de Octubre" University Hospital, Madrid, Spain
}

Edited by:

David Cano, Hospital Universitario

Virgen del Rocío, Spain

Reviewed by:

Carmen Blanco Aparicio, Spanish National Cancer Research Centre,

Spain

Rosario Perona, CSIC, Spain

*Correspondence:

Amancio Carnero, Instituto de

Biomedicina de Sevilla (IBiS), Hospital Universitario Virgen del Rocio,

Consejo Superior de Investigaciones Cientificas, Edificio IBIS, Avda.

Manuel Siurot s/n., Sevilla 41013,

Spain

e-mail: acarnero-ibis@us.es
When PI3K (phosphatidylinositol-3 kinase) is activated by receptor tyrosine kinases, it phosphorylates PIP2 to generate PIP3 and activates the signaling pathway. Phosphatase and tensin homolog deleted on chromosome 10 dephosphorylates PIP3 to PIP2, and thus, negatively regulates the pathway. AKT (v-akt murine thymoma viral oncogene homolog; protein kinase B) is activated downstream of PIP3 and mediates physiological processes. Furthermore, substantial crosstalk exists with other signaling networks at all levels of the $\mathrm{PI} 3 \mathrm{~K}$ pathway. Because of its diverse array, gene mutations, and amplifications and also as a consequence of its central role in several signal transduction pathways, the PI3Kdependent axis is frequently activated in many tumors and is an attractive therapeutic target. The preclinical testing and analysis of these novel therapies requires appropriate and well-tailored systems. Mouse models in which this pathway has been genetically modified have been essential in understanding the role that this pathway plays in the tumorigenesis process. Here, we review cancer mouse models in which the PI3K/AKT pathway has been genetically modified.

Keywords: cancer mouse models, PI3K/AKT, PTEN, genetically modified mice, tumorigenesis

\section{PTEN/PI3K/AKT PATHWAY}

Phosphatase and tensin homolog deleted on chromosome 10 (PTEN) is a dual lipid and protein phosphatase that dephosphorylates the lipid phosphatidylinositol-3,4,5-triphosphate (PIP3) (1), which is the product of PI3K. The overactivation or constitutive activation of PI3K as well as the loss of PTEN function results in the accumulation of cellular PIP3 and its activated downstream effectors, including PDK1 and AKT/PKB. The PI3K family is divided into four classes. The first three classes phosphorylate lipids while the class IV PI3K-related proteins (composed of ATM, ATR, mTOR, and DNA-PK) are serine-threonine kinases. In this review, we focus on the Class I proteins. This class is composed of heterodimers that consist of a catalytic subunit (p110) and a regulatory subunit ( $\mathrm{p} 85, \mathrm{p} 65$, or $\mathrm{p} 101)$. The Class I proteins can be further subdivided into two subclasses. Subclass Ia includes proteins that consist of $\mathrm{p} 110 \alpha, \mathrm{p} 110 \beta$, or $\mathrm{p} 110 \delta$ catalytic subunit and a regulatory subunit (p85, p65, or p55), and subclass Ib includes the heterodimer consisting of the p110 $\gamma$ catalytic subunit and the p101 regulatory subunit.

Physiological growth factors bind to the receptors, which triggers its cross-phosphorylation and attracts the regulatory subunit of the heterodimer to the site. These signaling events activate PI3K where it is in close proximity to its membrane substrate PIP2. The phosphorylation of PIP2 by PI3K to generate PIP3 triggers the binding of PIP3 to proteins that contain pleckstrin homology domains (PHD). PDK1 contains a C-terminal PHD, which binds to membrane-bound PIP3 and induces PDK1 activation. PDK1 phosphorylates AKT at the threonine 308 residue (T308). This signaling event primes AKT for phosphorylation at serine 473 (S473) by mTORC2 (the complex rictor/mTOR), which activates the AKT serine/threonine kinase activity. Activated AKT then phosphorylates its physiological substrates, which promotes survival, migration, cell cycle progression, and metabolism (Figure 1) (2-7). To date, hundreds of non-redundant AKT substrates have been discovered (8). The AKT family consists of three members, AKT1, AKT2, and AKT3 that are encoded by three different genes (9). Even though knock-out mice for the specific AKT isoforms have demonstrated that these three AKT isoforms have different physiological functions $(10,11)$; some functional redundancy still exists between them $(3,12,13)$.

The constitutive activation of AKT is important in PTENmediated tumorigenesis and several mechanisms have been proposed for its precise function in this process $(3,5,14-19)$. AKT-independent mechanisms of PTEN-mediated tumorigenesis, however, have also been proposed (19-22). Among these proposals, direct binding to p53 may promote PTEN stability (21). Furthermore, PTEN has been shown to dephosphorylate phosphotyrosyl and phosphothreonyl-containing substrates (23-25), and mutation altering this phosphatase activity has been found to be protumorigenic. PTEN is also found in the nucleus (26, 27) where it may contribute to tumorigenesis through a mechanism that is independent of PIP3 dephosphorylation (28). Nuclear PTEN has been shown to have phosphatase activity that downregulates the MAPK pathway and cyclin D1. Furthermore, the interaction between p53 and PTEN also occurs in the nucleus $(22,29)$. Additionally, other studies have shown that PTEN also interacts with PCAF and p300 transcriptional coactivators that function as histone acetyltransferases $(22,30)$.

PDK1 also has certain PIP3-dependent, AKT-independent functions. PTEN $(+/-)$ heterozygous mice, which have a reduced PDK1 expression level, develop fewer tumors (31). It has been shown that PDK1 phosphorylates all AGC kinase family members 


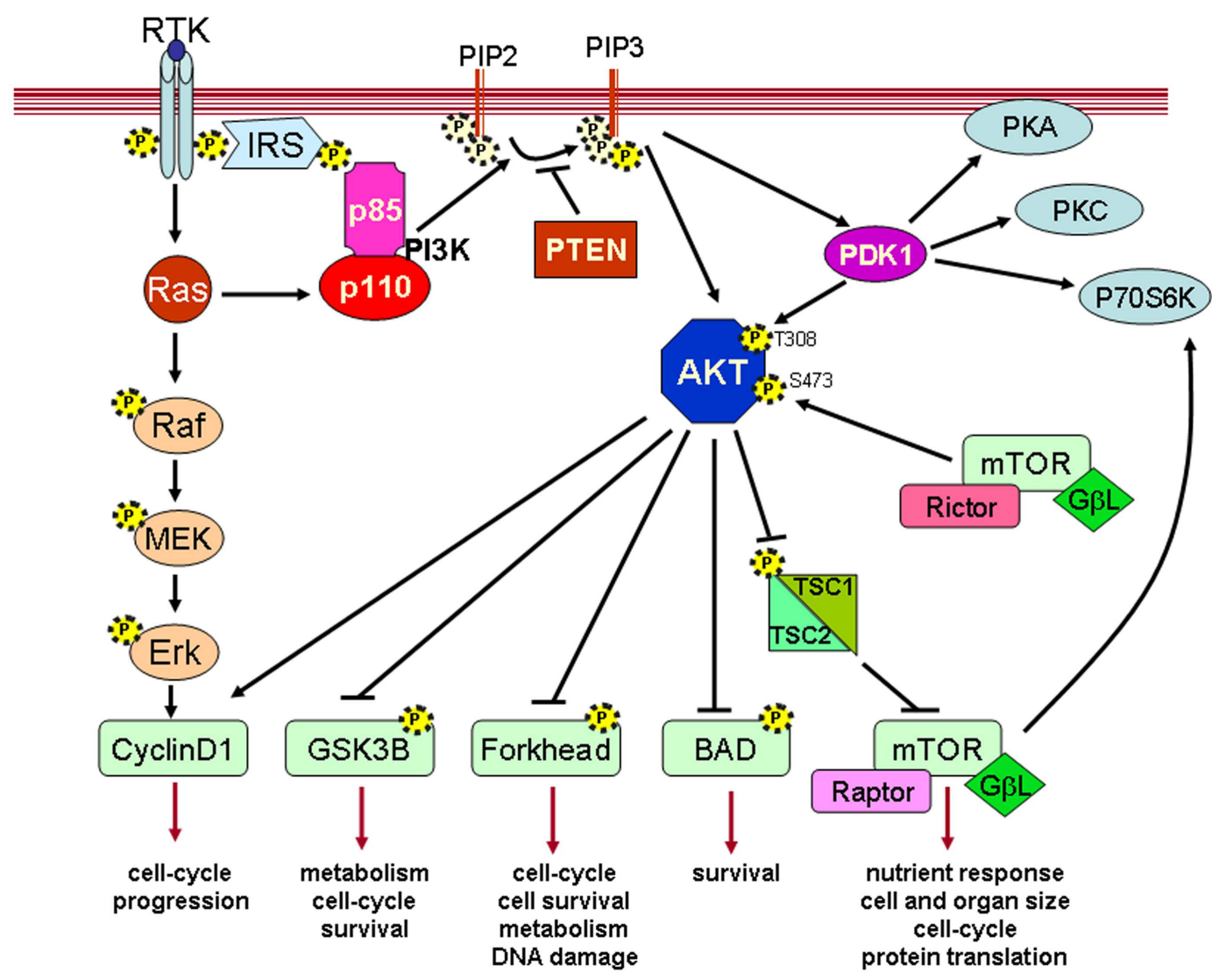

FIGURE 1 |A schematic diagram depicting the most representative signaling of the PI3K/AKT pathway

$(12,32)$. Furthermore, other PHD containing proteins are also recruited to PIP3, which indicates that other pathways are also affected by PI3K activation $(3,18)$.

Finally, this pathway may also be activated by RTKs and Gprotein-coupled receptors. Other tyrosine kinase receptors, such as BCR-ABL and ErbB2, and oncogenes, such as Ras, also signal through the PI3K pathway. These signaling pathways, however, have been reviewed elsewhere $(13,32)$. Therefore, we will focus on the main pathway members PTEN, PI3K, and AKT in this review.

\section{PI3K PATHWAY IN HUMAN TUMORS}

A loss of PTEN expression can result from several different types of mutations, such as an insertion into the sequence that alter the reading frame and promote early termination, deletions, or promoter methylation, which has been found in many tumors, especially metastatic human cancers $(7,33)$. Germline mutations in PTEN have been identified in familial cancer predisposition syndromes, such as Cowden, Bannayan-Riley-Ruvalcaba and Proteus-like syndromes (34-37). The PIK3CA gene (encoding the $\mathrm{p} 110 \alpha$ catalytic subunit of PI3K) has been found to be the recipient of many activating mutations in human tumors (33, 38). The mutations E542K, E545K, and H1047R have been found to be the three most frequent activating mutations. Although these mutations influence PI3K activity in different ways (39, 40), they all enhance catalytic activity (41). They activate AKT and promote transcription (42) that stimulates the oncogenic activity of the mutants $(43,44)$. Importantly, PIK3CA mutations have also been found in the non-tumoral tissue of several cancer patients (45). In superficial bladder cancer, however, certain modifications to PIK3CA are associated with better clinical outcomes, which are also affected by the coexpression of FGFR3 mutations (45). Other p110 isoforms have also been shown to be oncogenic when amplified, but no mutations have been currently identified (42-44).

Activating AKT1 mutations have also been reported to occur at a very low frequency. An AKT1-E17K mutation activates AKT1 by promoting its localization to the plasma membrane (46). The activation of PI3K and AKT by gene amplification occurs in many cancer types $(33,47)$, including breast $(48-50)$, ovarian $(49,51,52)$, pancreas (53), esophageal (54), and thyroid cancer (55) (Figure 2).

Every major protein in this pathway is mutated or amplified in a large variety of solid tumors, and these mutations are not exclusive. In many cases, multiple mutations are found in the same tumor (56-66) and this phenomenon is most likely a tissuespecific behavior. Furthermore, this finding suggests that different mutations alter different non-redundant pathways, which allows these different mutations to coexist in the same tumor. 


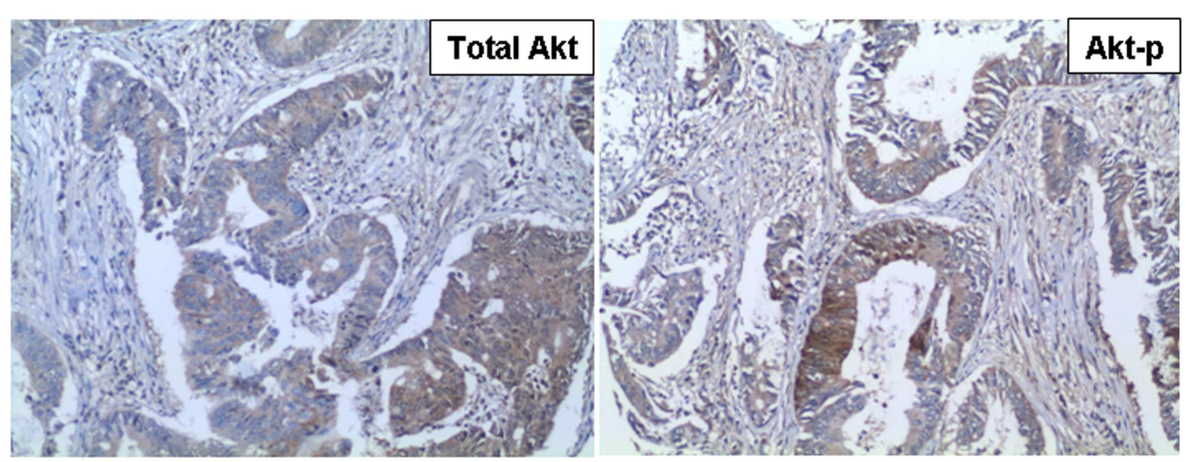

FIGURE 2 | Representative images of AKT-positive human tumors (Colorectal carcinoma). The left image (total AKT) shows the total level of AKT protein in the tumor cells. The right image (Akt-p) shows the level of AKT protein phosphorylated at S473.

\section{PTEN MODELS}

In the 1990s, gene knock-out studies demonstrated that PTEN acts as a tumor suppressor (67-70). PTEN homozygous knockout mice are embryonic lethal, but heterozygous PTEN+/mice demonstrate many of the features described in human cancer hereditary syndromes with defective PTEN. These mice develop tumors in multiple tissues, including breast tissue, the endometrium, and prostate, which is similar to the cancer predisposition pattern in human Cowden syndrome (67-70).

Tissue-specific PTEN-deletion models have been generated using LoxP/CRE technology. The tissue-specific loss of PTEN expression results in the development of specific tumors (12, 71-75).

Mouse model studies on the role that PTEN plays in the prostate have shown that a loss of PTEN expression is essential for initiating prostate cancer $(76,77)$, and that there are specific dose-dependent effects. For example, a complete loss of PTEN expression results in invasive prostate cancer with a long latency period (78) and metastasis (79).

This process, however, is more complicated. For example, a complete loss of PTEN expression also triggers cellular senescence through a p53-dependent mechanism $(73,80)$, and the combined loss of PTEN and p53 dramatically accelerates tumorigenesis and malignancy. In a prostate tumor model in which tumorigenesis is initiated by a loss of PTEN expression, the genetic loss of p110 $\beta$, but not $\mathrm{p} 110 \alpha$, is able to simultaneously reduce tumorigenesis and AKT activation (81).

The relationship between activation of the $\mathrm{p} 53$ pathway and PI3K pathway in vivo is extremely complex. For example, the epidermal-specific ablation of p53 results in spontaneous tumor development and induces the premature activation of AKT $(82,83)$, which then plays specific roles in the epithelial-mesenchymal transition and the metastatic spread stimulated by the tumors (84). In contrast, the mammary-specific deletion of the PTEN gene results in increased intra-lumina focal hyperplasia, which results from an increase in proliferation and dysplasia. This phenotype is similar to the phenotypes observed in hereditary PTEN-dependent syndromes (85). PTENnull mutant females consistently developed mammary tumors early in life.
A loss of one PTEN allele occurs in a large portion of human cancers, and PTEN heterozygous mice have demonstrated the importance of a dose reduction. In the female mice, $50 \%$ of PTEN heterozygous female mice develop mammary tumors, and most of these tumors demonstrate endometrial hyperplasia, which results in a $20 \%$ incidence of endometrial cancer. Consistent with the findings in prostate models, mice carrying deletions for PTEN and p53 in the endometrium develop aggressive cancer and have a shorter life span than mice carrying only a PTEN deletion (86).

MMTV-wnt1 transgenic mice in a PTEN heterozygous background develop mammary tumors faster than their parental strains (87). A reduced PTEN level also contributes to the growth of leiomyosarcomas (88) and double NF1/p53 KO mice develop high grade astrocytomas (89). Additionally, mice heterozygous for PTEN and p53 develop lymphomas with an onset similar to p53 null mice. This similarity may be because of the reduction in p53 stability that occurs in the absence of PTEN (21).

The loss of one Nkx3.1 allele in a heterozygous PTEN $(+/-)$ background results in the development of invasive adenocarcinomas and lymph node metastases (90), and these results are similar to the results obtained when c-Myc is overexpressed (91). These results may be similar because Nkx3.1 and Myc share many target genes in common (92). Knockout of Nkx3.1 alone, however, only results in epithelial hyperplasia and dysplasia that does not develop into an invasive carcinoma (93).

In advanced prostate cancer, the TGF $\beta /$ Smad 4 signaling pathway is activated upon the loss of PTEN expression. Consistently, the prostate-specific PTEN and Smad4 double knock-out results in the development of prostate cancer with metastasis (94). Furthermore, the expression of active telomerases in a double PTEN/p53 knock-out mouse results in bone metastases with $100 \%$ penetrance (95). An increase in the onset of prostate cancer is observed when PTEN expression is lost in combination with another oncogenic signal, such as HER2, ERG, K-Ras, SOX9, and Bmil. Like a loss in Nkx3.1 expression and overexpression of Myc, the expression levels of many of these oncogenic signals have been shown to be reduced in advanced prostate cancers in humans (71).

The mammary glands from heterozygous PTEN knock-out mouse form basal-like mammary tumors (96). Similarly, a loss of PTEN protein expression is also associated with the basal-like 
breast cancer subtype in humans. Additionally, there are certain PTEN mutations that are commonly found in BRCA1-deficient breast cancers (96). In contrast, an increase in the PTEN expression level reduces the Wnt-1-induced onset of mammary tumors (97), which indicates that the PI3K/AKT pathway is a good target candidate for treating mammary cancer. Furthermore, the development of multifocal, highly metastatic mammary tumors is greatly accelerated in a transgenic mouse model that overexpresses ErbB2 in the same mammary epithelial cells in which PTEN has been deleted. These tumors demonstrate solid nodular growth of the intermediate cells with central necrosis and an ErbB2-type pathology. PTEN-null/ErbB2-induced tumorigenesis has also been associated with increased angiogenesis and the constitutive activation of the Akt node. Tumors generated from PTEN-null/ErbB2-derived tumors, however, demonstrate characteristics similar to luminal-type human breast cancers (98).

The T cell-specific deletion of PTEN results in elevated levels of $B$ cells and CD4+ T cells in the periphery and increases thymic cellularity, resulting in CD4+ T cell lymphomas (99). PTEN-deficient $\mathrm{T}$ cells were hyperproliferative, highly resistant to apoptosis, and had increased levels of phosphorylated AKT and ERK. Backman and colleagues generated a brain-specific PTEN-deleted mouse model that developed seizures and ataxia early in life and died shortly (100). This brain-specific PTEN knock-out mouse can be used as an animal model for the human Lhermitte-Duclos disease (100). Furthermore, the inactivation of the $\mathrm{pRb}$ pathway in brain astrocytes (through the expression of a truncated SV40 T antigen) induces the development of malignant astrocytomas in mice, and the development of these astrocytomas is accelerated in a PTEN-null background $(101,102)$.

Furthermore, it has been shown that there are important regulatory mechanisms between the PTEN/PI3K/AKT pathway and the cell cycle that can be clearly observed at the physiological level. For example, PTEN overexpression results in cell cycle arrest through a pRb-dependent mechanism (103). This relationship, however, is more complicated. It has also been shown that the specific inducible loss of $\mathrm{pRb}$ and $\mathrm{p} 107$ reduces the PTEN expression level (104), and this finding is most likely caused by impairing the p53-dependent activation of PTEN gene transcription (105). More importantly, this process results in squamous tumor development, which can be attenuated by rapamycin treatment (104).

Phosphatase and tensin homolog deleted on chromosome 10 knock-out mice display highly proliferative ductal structures that progressively replace the acini in the pancreas. These proliferative structures express Pdx1 and Hes1, which are two markers for pancreatic progenitor cells. Moreover, a percentage of these mice develop PanIN lesions in the pancreas and demonstrate a low frequency of malignant transformation (106).

In a conditional PTEN knock-out mouse in which PTEN expression is specifically deleted in the epidermis, chemical carcinogenesis-induced tumors develop into carcinomas (107). The mechanism underlying these events involves a failure in apoptosis and an increase in AKT and ERK activity $(108,109)$. Consistent with these findings, the inactivation of PTEN in the lungs accelerates oncogenic K-Ras-initiated tumorigenesis (110).

The inactivation of one PTEN allele also works in conjunction with hormone treatments to increase the severity of prostate, bladder, and ureteral urothelial hyperplasia (111-113). These findings are consistent with a study showing that the prostate epithelial cells of castrated PTEN(-/-) mice will undergo massive apoptosis, unless they are treated with an mTOR inhibitor (114). In PTEN(+/-); Nkx3.1(-/-) mice, the prostates were unaffected by castration (115). Altogether, these findings suggest that a loss of PTEN expression in prostate cancer is sufficient for establishing androgen-independence.

\section{PI3K MODELS}

The initial models inducing activation of the PI3K signaling pathway targeted the heart using tissue-specific expression of an activated form of $\mathrm{p} 110 \alpha$ (116). This specific activation resulted in an increase in cell size, which resulted in an increase in heart size. Taken together with studies using AKT models, these studies stress the importance of PI3K signaling in determining cell size. Later, it was demonstrated that the activation of PI3K through the expression of $\mathrm{p} 65$, which is a constitutively active truncated form of $\mathrm{p} 85$ that activates the $\mathrm{p} 110 \alpha \beta$ and $\delta$ isoforms, induces a lymphoproliferative disorder that progresses to lymphoma when the mice are crossed with p53 null mice (117). Similarly, a form of $\mathrm{p} 110 \alpha$ that is constitutively active because it is directly targeted to the membrane of epithelial cells in the prostate did not induce tumor development (118), but some hyperplasia in this tissue was observed. In contrast, targeting p110 $\alpha$ to the membranes of epithelial cells in the mammary glands predisposes the mammary glands to neoplastic transformation (119). This mild tumor phenotype becomes more severe in the presence of an active CDK4-allele mutant (R24C). Activation of the CDK4/Rb/E2F pathway and PI3K-pathway results in increased tumorigenesis $(74,119)$.

Transgenic mice that carry the PIK3CA-H1047R mutation in the Rosa 26 locus express the PI3Ka mutation in mammary epithelial cells when CRE expression is under the control of the MMTV promoter and develop adenosquamous carcinoma or adenomyoepithelioma $(120,121)$. When this transgenic mouse was bred into a heterozygous p53(+/-) background, tumorigenesis was accelerated and the tumors were mainly adenosquamous carcinomas (120). The expression of the PIK3CA-H1047R mutation in the luminal cells of the mammary epithelium induced the development of tumors with several different phenotypes, including ER-expressing tumors (122-124). These PI3K-dependent tumors have been used in pharmacological intervention studies (125). Similar to the observations made in other PI3K-mutant models, the tetracycline-inducible expression of human PIK3CA-H1047R in the mammary gland induced the development of adenocarcinomas and adenosquamous carcinomas (126). After downregulating PI3K signaling by removing the doxycycline, tumorigenesis was inhibited. Two-thirds of the tumors, however, resumed growth even though the PIK3CA-H1047R mutant protein was inactivated. This finding may partially be the result of Met amplifications, which promote tumor survival. Other tumors have also been shown to be independent of PI3K signaling because of Myc amplifications (126). This same human PIK3CA-H1047R model under the control of tetracycline-inducible expression in the lungs has been shown to induce the development of lung adenocarcinomas (127). After the doxycycline is removed from this tissue, two-thirds of the tumor growth was inhibited as a result of 
PIK3CA-H1047R inactivation. In the mammary gland, the expression of the PIK3CA-E545K mutant induces the development of tumors that express basal and luminal markers, but these tumors demonstrate less potent oncogenic activity in vivo than the tumors that developed because of the H1047R mutant (128).

The pancreas-specific expression of the PIK3CA-H1047R mutant in acinar cells using an elastase-1 Cre driver line (129) induces premalignant PanIN and acinar-to-ductal metaplasia (106) at a similar frequency as the expression of oncogenic K-RasG12D and phenocopies the K-RasG12D-induced metastatic ductal adenocarcinoma. Furthermore, when the oncogenic PIK3CA-H1047R mutant is expressed in the pancreas, a senescence program is activated, which can be bypassed by a loss of Cdkn2a.

PI3K has been shown to be an important effector of oncogenic Ras (130). Mutant oncogenic Ras physically interacts with the p110a catalytic subunit to trigger its own activation. The RasPI3K interaction plays an important role in Ras-induced skin and lung carcinogenesis (131). Disrupting the direct Ras/p110 $\alpha$ interaction by expressing a PIK3CA allele carrying mutations in two residues that are critical for the Ras-p110 $\alpha$ interaction, T208D, and K227A, dramatically decreases the number of Ras-induced lung adenomas and papillomas (131). Most of these genetically altered mice, however, die perinatally, and this tumor-reduction effect was only observed in the small number of surviving mice. Furthermore, $\mathrm{p} 110 \alpha$ is also required for neo-angiogenesis (132), and the observed effects on tumor reduction may be because of its effects in the stroma. Disrupting the interaction between Ras and $\mathrm{p} 110 \alpha$ may alter the vasculature, which could significantly affect the phenotype observed in this model. Consistent with this proposal, a study using transgenic mice with K-RasG12D-driven lung tumors demonstrated that inhibition of the PI3K-mTOR axis in vivo produced poor efficacy results with only a marginal reduction in lung tumors (127). In contrast, targeting the PI3K pathway in a K-RasG12D-driven PDAC model produced a good response by inhibiting the initiation and progression of tumors (133).

\section{AKT MODELS}

The mechanism underlying the induction of tumor development by activated AKT appears to be more complicated and depends on the AKT level, target tissue, and possibly even the molecular context. Despite the apparent linear PTEN-PI3K-PDK1-AKT pathway and the proposed relevance of AKT in the PTEN pathway, no consistent results have been found when comparing PTEN deletion with activated AKT transgenes in certain tissues (12). Several groups, including our group, have generated transgenic mice that specifically express different forms of constitutively active AKT in the mammary gland using an epithelial-specific MMTV promoter (12, 134-136). Unlike the PTEN conditional knock-out mice, no increases in the tumor growth rates were observed $(12,135)$. And this result was observed at the different levels of active AKT generated in the different models (137). Activation of the AKT pathway, however, did result in involution defects, which is consistent with PTEN KO mouse phenotype. It has been proposed that the phenotypic differences observed between mammary targeted PTEN KO and mammary-specific activation of AKT are because an optimal level of AKT activation has not yet been generated in an animal model. An activation level that is too low will not activate the oncogenic pathway, and an activation level that is too high will activate the fail-safe mechanism of cellular senescence. It has been shown that AKT activation leads to p53- or p27-dependent senescence $(73,80,138)$ and does not reach the actual physiological levels. Furthermore, it is also possible that transgenic AKT activation does not occur in the appropriate target cell. Perhaps, the cells in which AKT activation will induce a tumor are not the same cells in which PTEN loss of expression will. The increase in the preneoplastic phenotype observed because of AKT activation was not affected by a loss of p27 or p53 (137). The coexpression of the p53 mutant p53-R172H and activated AKT significantly increased the size of mammary carcinomas; however, this coexpression was not sufficient to promote full penetrance of the tumorigenic phenotype (137). The results from a molecular analysis suggest that the tumors observed in the AKT-activated, p53(R172H) mice result from stimulating $\mathrm{p} 53(\mathrm{R} 172 \mathrm{H})$ initiated tumors and not from the AKT-induced bypass of oncogenic senescence (137). In these models, it appears that AKT-induced oncogenic senescence is more dependent on pRb than p53 because most of the tumors carrying activated AKT do not express the p16INK4a protein.

Other tissues, however, are more susceptible to tumorigenesis upon AKT activation. AKT is an essential node in mouse skin carcinogenesis that promotes the development of tumors (108). Additionally, a constitutively active AKT transforms keratinocytes by activating transcriptional and post-transcriptional mechanisms (139). The AKT activation level has also been shown to have a dose effect in another mouse model. In this model, the individuals with the highest levels of AKT activity developed spontaneous epithelial tumors in multiple organs as they aged. Furthermore, the expression of either wtAKT or myr-AKT in the epidermal basal cells dramatically enhanced the animal's susceptibility to DMBATPA-induced skin carcinogenesis (109). Altogether, these findings show that the deregulation of AKT expression in combination with alterations in the signaling pathways and gene expression can result in tumor development and an enhanced response to chemical carcinogenesis (109).

Accordingly, mice expressing a constitutively active AKT in combination with loss of $\mathrm{p} 53$ expression in the stratified epithelia develop oral cavity tumors that are similar to human head and neck squamous cell carcinomas (HNSCCs) (73) (Figure 3). These lesions become malignant as a result of the subsequent loss of p53 expression. Importantly, the mouse oral tumors closely resemble the human tumors as they demonstrate activation of the nuclear factor- $\kappa$ B and STAT- 3 pathways, a decrease in TGF- $\beta$ type II receptor expression, and a high metastatic potential by their ability to colonize regional lymph nodes (73).

The stem cells of the hair follicle have been identified as a potential initiation site for skin cancer. These cells are localized in the bulge of the hair follicle and alternate between periods of quiescence and proliferation until they differentiate. The expression of a constitutively active AKT results in several physiological changes in these bulge stem cells, such as increased sensitivity to proliferative signals and changes in cell migration and metabolism that causes them to exit from quiescence (140). These changes are similar to those changes observed in human cancer cells. 

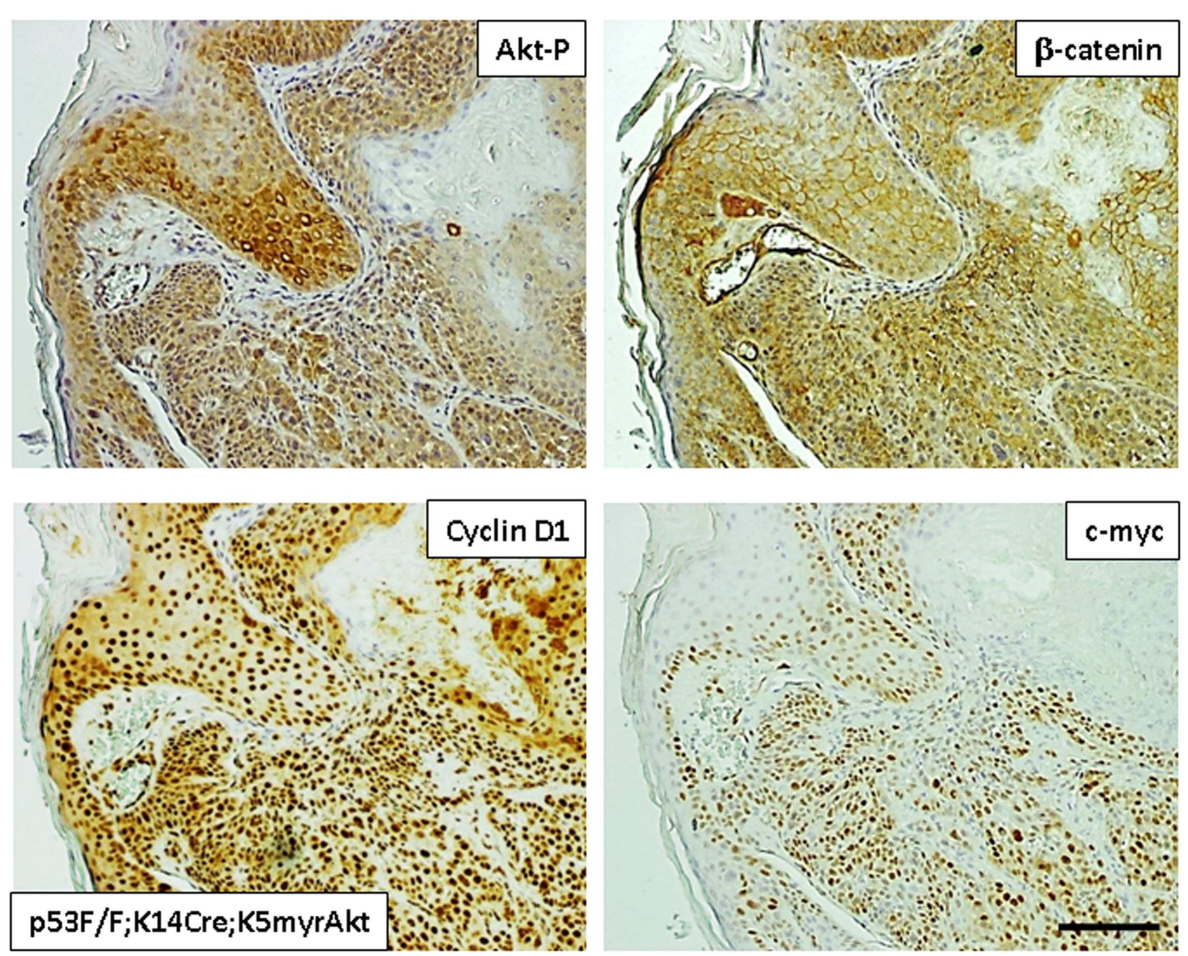

FIGURE 3 | Representative images of squamous skin tumors generated in transgenic mice expressing active AKT (myr-AKT) in K14-positive tissues (K14Cre) and a p53 null background (p53F/F). The images show tumors stained for AKT phosphorylated at S473 (Akt-p), $\beta$-catenin, cyclin D1, and c-myc.

The expression of activated AKT in the prostate also increases the proliferative capacity of the cells, which results in prostate intraepithelial neoplasia (PIN) $(118,141)$ even though no malignant tumors were observed. This mouse lesion has a gene expression profile that resembles the expression profile of the human prostate cancer transcriptome despite their non-malignant status. This finding indicates that the PI3K-AKT pathway plays an important role in prostate cancer development but that other additional factors are also necessary for the development of prostatic adenocarcinomas. For example, the coexpression of activated Ras and activated AKT causes glioblastome multiforme in mice, which is not observed in mice when these oncogenes are expressed alone (142). Mice with mammary gland-specific AKT1 expression under the control of the MMTV promoter that are orally treated with the carcinogen DMBA develop ER $\alpha$-positive tumors that closely resemble Era-associated human tumors (12). Furthermore, in a mammary gland-specific ErbB2 expression model, tumorigenesis is reduced in an AKT1 null background (143) and the concomitant expression of activated AKT accelerates the development of these ErbB2-induced tumors $(135,144,145)$. The expression of AKT1, however, also reduces ErbB2-induced lung metastasis. The mammary-specific expression of polyoma middle $\mathrm{T}$ antigen promotes the growth of metastatic mammary tumors that are of multifocal origin (146). When the antigen is mutated to reduce its ability to activate $\mathrm{PI} 3 \mathrm{~K}$, tumorigenesis is reduced and most of the lesions found to demonstrate hyperplasia and a high level of apoptosis. Finally, when this defective polyoma Middle
$\mathrm{T}$ antigen $(\triangle \mathrm{PI} 3 \mathrm{~K})$ is coexpressed with active $\mathrm{AKT}$, accelerated tumorigenesis is once again observed (147).

\section{FUTURE DIRECTIONS}

Most of the mouse models use tissue-specific expression of PTEN, AKT, or PI3K and rarely manipulate their expression by manipulating their regulators. Furthermore, this pathway is considered to be linear in most of the in vivo studies and an insufficient amount of attention has focused on the nuclear effects of PTEN or on the AKT-independent effects of PI3K and PDK1. For example, very informative mouse model studies on the nuclear functions of PTEN could be conducted by knocking in PTEN nuclear mutants. Other informative studies could be conducted by knocking in other p110-alpha mutants or other proteins involved in the metabolism of phospholipids. Additionally, the roles that specific PI3K and AKT isoforms play in the tissuespecific phenotypes induced by PTEN are also poorly understood. Finally, studies that combine PTEN deletions or PI3K mutants with other functionally related but AKT-independent proteins may elucidate the PIP3-dependent cancer activities of these genes.

\section{ACKNOWLEDGMENTS}

The Amancio Carnero lab is supported by grants from the Spanish Ministry of Economy and Competitivity, ISCIII (Fis: PI12/00137, RTICC: RD12/0036/0028), Consejeria de Ciencia e Innovacion (CTS-6844 and CTS-1848), and Consejeria de Salud of the Junta 
de Andalucia (PI-0135-2010 and PI-0306-2012). The Jesus M. Paramio lab is funded by the Spanish Ministry of Economy and Competitivity grants SAF2012-34378 and SAF2011-26122-C0201, Comunidad Autónoma de Madrid grants S2006/BIO-0232 and S2010/BMD-2470 (Oncocycle Programs), MSyC grants ISCIIIRETIC RD06/0020/0029 and RD12/0036/0009, and Fundación Sandra Ibarra.

\section{REFERENCES}

1. Maehama T, Dixon JE. The tumor suppressor, PTEN/MMAC1, dephosphorylates the lipid second messenger, phosphatidylinositol 3,4,5-trisphosphate. J Biol Chem (1998) 273:13375-8. doi:10.1074/jbc.273.22.13375

2. Dahia PL. PTEN, a unique tumor suppressor gene. Endocr Relat Cancer (2000) 7:115-29. doi:10.1677/erc.0.0070115

3. Downward J. PI 3-kinase, Akt and cell survival. Semin Cell Dev Biol (2004) 15:177-82. doi:10.1016/j.semcdb.2004.01.002

4. Kandel ES, Hay N. The regulation and activities of the multifunctional serine/threonine kinase Akt/PKB. Exp Cell Res (1999) 253:210-29. doi:10.1006/ excr. 1999.4690

5. Plas DR, Thompson CB. Akt-dependent transformation: there is more to growth than just surviving. Oncogene (2005) 24:7435-42. doi:10.1038/sj.onc. 1209097

6. Stokoe D. PTEN. Curr Biol (2001) 11:R502. doi:10.1016/S0960-9822(01) 00303-7

7. Vivanco I, Sawyers CL. The phosphatidylinositol 3-Kinase AKT pathway in human cancer. Nat Rev Cancer (2002) 2:489-501. doi:10.1038/nrc839

8. Manning BD, Cantley LC. AKT/PKB signaling: navigating downstream. Cell (2007) 129:1261-74. doi:10.1016/j.cell.2007.06.009

9. Datta SR, Brunet A, Greenberg ME. Cellular survival: a play in three Akts. Genes Dev (1999) 13:2905-27. doi:10.1101/gad.13.22.2905

10. Dummler B, Tschopp O, Hynx D, Yang ZZ, Dirnhofer S, Hemmings BA. Life with a single isoform of Akt: mice lacking Akt2 and Akt3 are viable but display impaired glucose homeostasis and growth deficiencies. Mol Cell Biol (2006) 26:8042-51. doi:10.1128/MCB.00722-06

11. Dummler B, Hemmings BA. Physiological roles of PKB/Akt isoforms in development and disease. Biochem Soc Trans (2007) 35:231-5. doi:10.1042/ BST0350231

12. Blanco-Aparicio C, Renner O, Leal JF, Carnero A. PTEN, more than the AKT pathway. Carcinogenesis (2007) 28:1379-86. doi:10.1093/carcin/bgm052

13. Carnero A. The PKB/AKT pathway in cancer. Curr Pharm Des (2010) 16:34-44. doi:10.2174/138161210789941865

14. Gottlieb TM, Leal JF, Seger R, Taya Y, Oren M. Cross-talk between Akt, p53 and Mdm2: possible implications for the regulation of apoptosis. Oncogene (2002) 21:1299-303. doi:10.1038/sj.onc. 1205181

15. Mayo LD, Donner DB. A phosphatidylinositol 3-kinase/Akt pathway promotes translocation of Mdm2 from the cytoplasm to the nucleus. Proc Natl Acad Sci U S A (2001) 98:11598-603. doi:10.1073/pnas.181181198

16. Oren M, Damalas A, Gottlieb T, Michael D, Taplick J, Leal JF, et al., Regulation of p53: intricate loops and delicate balances. Biochem Pharmacol (2002) 64:865-71. doi:10.1016/S0006-2952(02)01149-8

17. Radu A, Neubauer V, Akagi T, Hanafusa H, Georgescu MM. PTEN induces cell cycle arrest by decreasing the level and nuclear localization of cyclin D1. Mol Cell Biol (2003) 23:6139-49. doi:10.1128/MCB.23.17.6139-6149.2003

18. Stiles B, Groszer M, Wang S, Jiao J, Wu H. PTENless means more. Dev Biol (2004) 273:175-84. doi:10.1016/j.ydbio.2004.06.008

19. Weng L, Brown J, Eng C. PTEN induces apoptosis and cell cycle arrest through phosphoinositol-3-kinase/Akt-dependent and -independent pathways. Hum Mol Genet (2001) 10:237-42. doi:10.1093/hmg/10.3.237

20. Chang CJ, Freeman DJ, Wu H. PTEN regulates Mdm2 expression through the P1 promoter. J Biol Chem (2004) 279:29841-8. doi:10.1074/jbc.M401488200

21. Freeman DJ, Li AG, Wei G, Li HH, Kertesz N, Lesche R, et al., PTEN tumor suppressor regulates p53 protein levels and activity through phosphatasedependent and -independent mechanisms. Cancer Cell (2003) 3:117-30. doi:10.1016/S1535-6108(03)00021-7

22. Li AG, Piluso LG, Cai X, Wei G, Sellers WR, Liu X. Mechanistic insights into maintenance of high p53 acetylation by PTEN. Mol Cell (2006) 23:575-87. doi:10.1016/j.molcel.2006.06.028
23. Li J, Yen C, Liaw D, Podsypanina K, Bose S, Wang SI, et al., PTEN, a putative protein tyrosine phosphatase gene mutated in human brain, breast, and prostate cancer. Science (1997) 275:1943-7. doi:10.1126/science.275.5308.1943

24. Myers MP, Stolarov JP, Eng C, Li J, Wang SI, Wigler MH, et al., P-TEN, the tumor suppressor from human chromosome 10q23, is a dual-specificity phosphatase. Proc Natl Acad Sci U S A (1997) 94:9052-7. doi:10.1073/pnas.94.17.9052

25. Myers MP, Pass I, Batty IH, Van der Kaay J, Stolarov JP, Hemmings BA, et al., The lipid phosphatase activity of PTEN is critical for its tumor suppressor function. Proc Natl Acad Sci U S A (1998) 95:13513-8. doi:10.1073/pnas.95.23.13513

26. Baker SJ. PTEN enters the nuclear age. Cell (2007) 128:25-8. doi:10.1016/j.cell. 2006.12.023

27. Gil A, Andres-Pons A, Pulido R. Nuclear PTEN: a tale of many tails. Cell Death Differ (2007) 14:395-9. doi:10.1038/sj.cdd.4402073

28. Lindsay Y, McCoull D, Davidson L, Leslie NR, Fairservice A, Gray A, et al., Localization of agonist-sensitive PtdIns (3,4,5)P3 reveals a nuclear pool that is insensitive to PTEN expression. J Cell Sci (2006) 119:5160-8. doi:10.1242/jcs.000133

29. Lian Z, Di Cristofano A. Class reunion: PTEN joins the nuclear crew. Oncogene (2005) 24:7394-400. doi:10.1038/sj.onc.1209089

30. Okumura K, Mendoza M, Bachoo RM, DePinho RA, Cavenee WK, Furnari FB. PCAF modulates PTEN activity. J Biol Chem (2006) 281:26562-8. doi:10.1074/ jbc.M605391200

31. Bayascas JR, Leslie NR, Parsons R, Fleming S, Alessi DR. Hypomorphic mutation of PDK1 suppresses tumorigenesis in PTEN $( \pm)$ mice. Curr Biol (2005) 15:1839-46. doi:10.1016/j.cub.2005.08.066

32. Carnero A, Blanco-Aparicio C, Renner O, Link W, Leal JF. The PTEN/PI3K/AKT signalling pathway in cancer, therapeutic implications. Curr Cancer Drug Targets (2008) 8:187-98. doi:10.2174/156800908784293659

33. Parsons DW, Wang TL, Samuels Y, Bardelli A, Cummins JM, DeLong L, et al., Colorectal cancer: mutations in a signalling pathway. Nature (2005) 436:792. doi:10.1038/436792a

34. Liaw D, Marsh DJ, Li J, Dahia PL, Wang SI, Zheng Z, et al., Germline mutations of the PTEN gene in Cowden disease, an inherited breast and thyroid cancer syndrome. Nat Genet (1997) 16:64-7. doi:10.1038/ng0597-64

35. Marsh DJ, Kum JB, Lunetta KL, Bennett MJ, Gorlin RJ, Ahmed SF, et al., PTEN mutation spectrum and genotype-phenotype correlations in Bannayan-RileyRuvalcaba syndrome suggest a single entity with Cowden syndrome. Hum Mol Genet (1999) 8:1461-72. doi:10.1093/hmg/8.8.1461

36. Nelen MR, van Staveren WC, Peeters EA, Hassel MB, Gorlin RJ, Hamm H, et al., Germline mutations in the PTEN/MMAC1 gene in patients with Cowden disease. Hum Mol Genet (1997) 6:1383-7. doi:10.1093/hmg/6.8.1383

37. Schrager CA, Schneider D, Gruener AC, Tsou HC, Peacocke M. Clinical and pathological features of breast disease in Cowden's syndrome: an underrecognized syndrome with an increased risk of breast cancer. Hum Pathol (1998) 29:47-53. doi:10.1016/S0046-8177(98)90389-6

38. Samuels Y, Wang Z, Bardelli A, Silliman N, Ptak J, Szabo S, et al., High frequency of mutations of the PIK3CA gene in human cancers. Science (2004) 304:554. doi:10.1126/science.1096502

39. Zhao L, Vogt PK. Class I PI3K in oncogenic cellular transformation. Oncogene (2008) 27:5486-96. doi:10.1038/onc.2008.244

40. Zhao L, Vogt PK. Hot-spot mutations in p110alpha of phosphatidylinositol 3-kinase (pI3K): differential interactions with the regulatory subunit $\mathrm{p} 85$ and with RAS. Cell Cycle (2010) 9:596-600. doi:10.4161/cc.9.3.10599

41. Kang S, Bader AG, Vogt PK. Phosphatidylinositol 3-kinase mutations identified in human cancer are oncogenic. Proc Natl Acad Sci U S A (2005) 102:802-7. doi:10.1073/pnas.0408864102

42. Link W, Rosado A, Fominaya J, Thomas JE, Carnero A. Membrane localization of all class I PI 3-kinase isoforms suppresses c-Myc-induced apoptosis in Rat1 fibroblasts via Akt. J Cell Biochem (2005) 95:979-89. doi:10.1002/jcb.20479

43. Bader AG, Kang S, Vogt PK. Cancer-specific mutations in PIK3CA are oncogenic in vivo. Proc Natl Acad Sci U S A (2006) 103:1475-9. doi:10.1073/pnas. 0510857103

44. Zhao JJ, Liu Z, Wang L, Shin E, Loda MF, Roberts TM. The oncogenic properties of mutant p110alpha and p110beta phosphatidylinositol 3-kinases in human mammary epithelial cells. Proc Natl Acad Sci U S A (2005) 102:18443-8. doi:10.1073/pnas.0508988102

45. Dueñas M, Martínez-Fernández M, García-Escudero R, Villacampa F, Marqués M, Saiz-Ladera C, et al., PIK3CA gene alterations in bladder cancer are frequent and associate with reduced recurrence in non-muscle invasive tumors. Mol Carcinog (2013). doi:10.1002/mc.22125 
46. Carpten JD, Faber AL, Horn C, Donoho GP, Briggs SL, Robbins CM, et al., A transforming mutation in the pleckstrin homology domain of AKT1 in cancer. Nature (2007) 448:439-44. doi:10.1038/nature05933

47. Broderick DK, Di C, Parrett TJ, Samuels YR, Cummins JM, McLendon RE, et al., Mutations of PIK3CA in anaplastic oligodendrogliomas, highgrade astrocytomas, and medulloblastomas. Cancer Res (2004) 64:5048-50. doi:10.1158/0008-5472.CAN-04- 1170

48. Bachman KE, Argani P, Samuels Y, Silliman N, Ptak J, Szabo S, et al., The PIK3CA gene is mutated with high frequency in human breast cancers. Cancer Biol Ther (2004) 3:772-5. doi:10.4161/cbt.3.8.994

49. Campbell IG, Russell SE, Choong DY, Montgomery KG, Ciavarella ML, Hooi CS, et al., Mutation of the PIK3CA gene in ovarian and breast cancer. Cancer Res (2004) 64:7678-81. doi:10.1158/0008-5472.CAN-04-2933

50. Kirkegaard T, Witton CJ, McGlynn LM, Tovey SM, Dunne B, Lyon A, et al., AKT activation predicts outcome in breast cancer patients treated with tamoxifen. J Pathol (2005) 207:139-46. doi:10.1002/path.1829

51. Nakayama K, Nakayama N, Kurman RJ, Cope L, Pohl G, Samuels Y, et al., Sequence mutations and amplification of PIK3CA and AKT2 genes in purified ovarian serous neoplasms. Cancer Biol Ther (2006) 5:779-85. doi:10.4161/cbt. 5.7.2751

52. Xing D, Orsulic S. A genetically defined mouse ovarian carcinoma model for the molecular characterization of pathway-targeted therapy and tumor resistance. Proc Natl Acad Sci U S A (2005) 102:6936-41. doi:10.1073/pnas.0502256102

53. Asano T, Yao Y, Zhu J, Li D, Abbruzzese JL, Reddy SA. The PI 3-kinase/Akt signaling pathway is activated due to aberrant Pten expression and targets transcription factors NF-kappaB and c-Myc in pancreatic cancer cells. Oncogene (2004) 23:8571-80. doi:10.1038/sj.onc. 1207902

54. Okano J, Snyder L, Rustgi AK. Genetic alterations in esophageal cancer. Methods Mol Biol (2003) 222:131-45. doi:10.1385/1-59259-328-3:131

55. Garcia-Rostan G, Costa AM, Pereira-Castro I, Salvatore G, Hernandez R, Hermsem MJ, et al., Mutation of the PIK3CA gene in anaplastic thyroid cancer. Cancer Res (2005) 65:10199-207. doi:10.1158/0008-5472.CAN-04-4259

56. Berns K, Horlings HM, Hennessy BT, Madiredjo M, Hijmans EM, Beelen K, et al., A functional genetic approach identifies the PI3K pathway as a major determinant of trastuzumab resistance in breast cancer. Cancer Cell (2007) 12:395-402. doi:10.1016/j.ccr.2007.08.030

57. Boyault S, Drouet Y, Navarro C, Bachelot T, Lasset C, Treilleux I, et al., Mutational characterization of individual breast tumors: TP53 and PI3K pathway genes are frequently and distinctively mutated in different subtypes. Breast Cancer Res Treat (2012) 132:29-39. doi:10.1007/s10549-011-1518-y

58. Cancer Genome Atlas Network. Comprehensive molecular portraits of human breast tumours. Nature (2012) 490:61-70. doi:10.1038/nature11412

59. Hollestelle A, Elstrodt F, Nagel JH, Kallemeijn WW, Schutte M. Phosphatidylinositol-3-OH kinase or RAS pathway mutations in human breast cancer cell lines. Mol Cancer Res (2007) 5:195-201. doi:10.1158/1541-7786. MCR-06-0263

60. Jensen JD, Knoop A, Laenkholm AV, Grauslund M, Jensen MB, Santoni-Rugiu E, et al., PIK3CA mutations, PTEN, and pHER2 expression and impact on outcome in HER2-positive early-stage breast cancer patients treated with adjuvant chemotherapy and trastuzumab. Ann Oncol (2012):2034-42. doi:10.1093/ annonc/mdr546

61. Li H, Zhu R, Wang L, Zhu T, Li Q, Chen Q, et al., PIK3CA mutations mostly begin to develop in ductal carcinoma of the breast. Exp Mol Pathol (2010) 88:150-5. doi:10.1016/j.yexmp.2009.09.016

62. Lopez-Knowles E, O’Toole SA, McNeil CM, Millar EK, Qiu MR, Crea P, et al., PI3K pathway activation in breast cancer is associated with the basal-like phenotype and cancer-specific mortality. Int J Cancer (2010) 126:1121-31. doi:10.1002/ijc. 24831

63. Saal LH, Holm K, Maurer M, Memeo L, Su T, Wang X, et al., PIK3CA mutations correlate with hormone receptors, node metastasis, and ERBB2, and are mutually exclusive with PTEN loss in human breast carcinoma. Cancer Res (2005) 65:2554-9. doi:10.1158/0008-5472-CAN-04-3913

64. Saal LH, Johansson P, Holm K, Gruvberger-Saal SK, She QB, Maurer M, et al., Poor prognosis in carcinoma is associated with a gene expression signature of aberrant PTEN tumor suppressor pathway activity. Proc Natl Acad Sci USA (2007) 104:7564-9. doi:10.1073/pnas.0702507104

65. Stemke-Hale K, Gonzalez-Angulo AM, Lluch A, Neve RM, Kuo WL, Davies M, et al., An integrative genomic and proteomic analysis of PIK3CA, PTEN, and
AKT mutations in breast cancer. Cancer Res (2008) 68:6084-91. doi:10.1158/ 0008-5472.CAN-07-6854

66. Yuan TL, Cantley LC. PI3K pathway alterations in cancer: variations on a theme. Oncogene (2008) 27:5497-510. doi:10.1038/onc.2008.245

67. Di Cristofano A, Pesce B, Cordon-Cardo C, Pandolfi PP. Pten is essential for embryonic development and tumour suppression. Nat Genet (1998) 19:348-55. doi:10.1038/1235

68. Podsypanina K, Ellenson LH, Nemes A, Gu J, Tamura M, Yamada KM, et al., Mutation of Pten/Mmacl in mice causes neoplasia in multiple organ systems. Proc Natl Acad Sci U S A (1999) 96:1563-8. doi:10.1073/pnas.96.4.1563

69. Stambolic V, Tsao MS, Macpherson D, Suzuki A, Chapman WB, Mak TW. High incidence of breast and endometrial neoplasia resembling human Cowden syndrome in pten \pm mice. Cancer Res (2000) 60:3605-11.

70. Suzuki A, de la Pompa JL, Stambolic V, Elia AJ, Sasaki T, del Barco Barrantes I, et al., High cancer susceptibility and embryonic lethality associated with mutation of the PTEN tumor suppressor gene in mice. Curr Biol (1998) 8:1169-78. doi:10.1016/S0960-9822(07)00488-5

71. Inoue K, Fry EA, Taneja P. Recent progress in mouse models for tumor suppressor genes and its implications in human cancer. Clin Med Insights Oncol (2013) 7:103-22. doi:10.4137/CMO.S10358

72. Kishimoto H, Hamada K, Saunders M, Backman S, Sasaki T, Nakano T, et al., Physiological functions of Pten in mouse tissues. Cell Struct Funct (2003) 28:11-21. doi:10.1247/csf.28.11

73. Moral M, Segrelles C, Lara MF, Martinez-Cruz AB, Lorz C, Santos M, et al., Akt activation synergizes with Trp53 loss in oral epithelium to produce a novel mouse model for head and neck squamous cell carcinoma. Cancer Res (2009) 69:1099-108. doi:10.1158/0008-5472.CAN-08-3240

74. Renner O, Blanco-Aparicio C, Carnero A. Genetic modelling of the PTEN/AKT pathway in cancer research. Clin Transl Oncol (2008) 10:618-27. doi:10.1007/ s12094-008-0262-1

75. Renner O, Carnero A. Mouse models to decipher the PI3K signaling network in human cancer. Curr Mol Med (2009) 9:612-25. doi:10.2174/ 156652409788488766

76. Carracedo A, Pandolfi PP. The PTEN-PI3K pathway: of feedbacks and crosstalks. Oncogene (2008) 27:5527-41. doi:10.1038/onc.2008.247

77. Carver BS, Pandolfi PP. Mouse modeling in oncologic preclinical and translational research. Clin Cancer Res (2006) 12:5305-11. doi:10.1158/1078-0432. CCR-06-0482

78. Wang S, Gao J, Lei Q, Rozengurt N, Pritchard C, Jiao J, et al., Prostate-specific deletion of the murine Pten tumor suppressor gene leads to metastatic prostate cancer. Cancer Cell (2003) 4:209-21. doi:10.1016/S1535-6108(03)00215-0

79. Freeman D, Lesche R, Kertesz N, Wang S, Li G, Gao J, et al., Genetic background controls tumor development in PTEN-deficient mice. Cancer Res (2006) 66:6492-6. doi:10.1158/0008-5472.CAN-05-4143

80. Chen Z, Trotman LC, Shaffer D, Lin HK, Dotan ZA, Niki M, et al., Crucial role of p53-dependent cellular senescence in suppression of Pten-deficient tumorigenesis. Nature (2005) 436:725-30. doi:10.1038/nature03918

81. Jia S, Liu Z, Zhang S, Liu P, Zhang L, Lee SH, et al., Essential roles of $\mathrm{PI}(3) \mathrm{K}$-p110beta in cell growth, metabolism and tumorigenesis. Nature (2008) 454:776-9. doi:10.1038/nature07091

82. Martinez-Cruz AB, Santos M, Lara MF, Segrelles C, Ruiz S, Moral M, et al., Spontaneous squamous cell carcinoma induced by the somatic inactivation of retinoblastoma and Trp53 tumor suppressors. Cancer Res (2008) 68:683-92. doi:10.1158/0008-5472.CAN-07-3049

83. Martínez-Cruz AB, Santos M, García-Escudero R, Moral M, Segrelles C, Lorz C, et al., Spontaneous tumor formation in Trp53-deficient epidermis mediated by chromosomal instability and inflammation. Anticancer Res (2009) 29: 3035-42.

84. Bornachea O, Santos M, Martinez-Cruz AB, Garcia-Escudero R, Duenas M, Costa C, et al., EMT and induction of miR-21 mediate metastasis development in Trp53-deficient tumours. Sci Rep (2012) 2:434. doi:10.1038/srep00434

85. Li G, Robinson GW, Lesche R, Martinez-Diaz H, Jiang Z, Rozengurt N, et al., Conditional loss of PTEN leads to precocious development and neoplasia in the mammary gland. Development (2002) 129:4159-70.

86. Daikoku T, Hirota Y, Tranguch S, Joshi AR, DeMayo FJ, Lydon JP, et al., Conditional loss of uterine Pten unfailingly and rapidly induces endometrial cancer in mice. Cancer Res (2008) 68:5619-27. doi:10.1158/0008-5472.CAN08- 1274 
87. Li Y, Podsypanina K, Liu X, Crane A, Tan LK, Parsons R, et al., Deficiency of Pten accelerates mammary oncogenesis in MMTV-Wnt-1 transgenic mice. BMC Mol Biol (2001) 2:2. doi:10.1186/1471-2199-2-2

88. Hernando E, Charytonowicz E, Dudas ME, Menendez S, Matushansky I, Mills J, et al., The AKT-mTOR pathway plays a critical role in the development of leiomyosarcomas. Nat Med (2007) 13:748-53. doi:10.1038/nm1560

89. Kwon CH, Zhao D, Chen J, Alcantara S, Li Y, Burns DK, et al., Pten haploinsufficiency accelerates formation of high-grade astrocytomas. Cancer Res (2008) 68:3286-94. doi:10.1158/0008-5472.CAN-07-6867

90. Abate-Shen C, Banach-Petrosky WA, Sun X, Economides KD, Desai N, Gregg JP, et al., Nkx3.1; Pten mutant mice develop invasive prostate adenocarcinoma and lymph node metastases. Cancer Res (2003) 63:3886-90.

91. Kim J, Eltoum IE, Roh M, Wang J, Abdulkadir SA. Interactions between cells with distinct mutations in c-MYC and Pten in prostate cancer. PLoS Genet (2009) 5:e1000542. doi:10.1371/journal.pgen.1000542

92. Anderson PD, McKissic SA, Logan M, Roh M, Franco OE, Wang J, et al., Nkx3.1 and Myc crossregulate shared target genes in mouse and human prostate tumorigenesis. J Clin Invest (2012) 122:1907-19. doi:10.1172/JCI58540

93. Bhatia-Gaur R, Donjacour AA, Sciavolino PJ, Kim M, Desai N, Young P, et al., Roles for Nkx3.1 in prostate development and cancer. Genes Dev (1999) 13:966-77. doi:10.1101/gad.13.8.966

94. Ding Z, Wu CJ, Chu GC, Xiao Y, Ho D, Zhang J, et al., SMAD4-dependent barrier constrains prostate cancer growth and metastatic progression. Nature (2011) 470:269-73. doi:10.1038/nature09677

95. Ding Z, Wu CJ, Jaskelioff M, Ivanova E, Kost-Alimova M, Protopopov A, et al., Telomerase reactivation following telomere dysfunction yields murine prostate tumors with bone metastases. Cell (2012) 148:896-907. doi:10.1016/j.cell.2012. 01.039

96. Saal LH, Gruvberger-Saal SK, Persson C, Lovgren K, Jumppanen M, Staaf J, et al., Recurrent gross mutations of the PTEN tumor suppressor gene in breast cancers with deficient DSB repair. Nat Genet (2008) 40:102-7. doi:10.1038/ng.2007.39

97. Zhao H, Cui Y, Dupont J, Sun H, Hennighausen L, Yakar S. Overexpression of the tumor suppressor gene phosphatase and tensin homologue partially inhibits wnt-1-induced mammary tumorigenesis. Cancer Res (2005) 65:6864-73. doi:10.1158/0008-5472.CAN-05-0181

98. Schade B, Rao T, Dourdin N, Lesurf R, Hallett M, Cardiff RD, et al., PTEN deficiency in a luminal ErbB-2 mouse model results in dramatic acceleration of mammary tumorigenesis and metastasis. J Biol Chem (2009) 284:19018-26. doi:10.1074/jbc.M109.018937

99. Suzuki A, Yamaguchi MT, Ohteki T, Sasaki T, Kaisho T, Kimura Y, et al., T cell-specific loss of Pten leads to defects in central and peripheral tolerance. Immunity (2001) 14:523-34. doi:10.1016/S1074-7613(01)00134-0

100. Backman SA, Stambolic V, Suzuki A, Haight J, Elia A, Pretorius J, et al., Deletion of Pten in mouse brain causes seizures, ataxia and defects in soma size resembling Lhermitte-Duclos disease. Nat Genet (2001) 29:396-403. doi:10.1038/ng782

101. Xiao A, Wu H, Pandolfi PP, Louis DN, Van Dyke T. Astrocyte inactivation of the $\mathrm{pRb}$ pathway predisposes mice to malignant astrocytoma development that is accelerated by PTEN mutation. Cancer Cell (2002) 1:157-68. doi:10.1016/S1535-6108(02)00029-6

102. Xiao A, Yin C, Yang C, Di Cristofano A, Pandolfi PP, Van Dyke T. Somatic induction of Pten loss in a preclinical astrocytoma model reveals major roles in disease progression and avenues for target discovery and validation. Cancer Res (2005) 65:5172-80. doi:10.1158/0008-5472.CAN-04-3902

103. Paramio JM, Navarro M, Segrelles C, Gomez-Casero E, Jorcano JL. PTEN tumour suppressor is linked to the cell cycle control through the retinoblastoma protein. Oncogene (1999) 18:7462-8. doi:10.1038/sj.onc.1203151

104. Costa C, Santos M, Segrelles C, Duenas M, Lara MF, Agirre X, et al., A novel tumor suppressor network in squamous malignancies. Sci Rep (2012) 2:828. doi: $10.1038 /$ srep00828

105. Stambolic V, MacPherson D, Sas D, Lin Y, Snow B, Jang Y, et al., Regulation of PTEN transcription by p53. Mol Cell (2001) 8:317-25. doi:10.1016/S10972765(01)00323-9

106. Eser S, Reiff N, Messer M, Seidler B, Gottschalk K, Dobler M, et al., Selective requirement of PI3K/PDK1 signaling for Kras oncogene-driven pancreatic cell plasticity and cancer. Cancer Cell (2013) 23:406-20. doi:10.1016/j.ccr.2013. 01.023
107. Yao D, Alexander CL, Quinn JA, Porter MJ, Wu H, Greenhalgh DA. PTEN loss promotes rasHa-mediated papillomatogenesis via dual up-regulation of AKT activity and cell cycle deregulation but malignant conversion proceeds via PTEN-associated pathways. Cancer Res (2006) 66:1302-12. doi:10.1158/ 0008-5472.CAN-05-2341

108. Segrelles C, Ruiz S, Perez P, Murga C, Santos M, Budunova IV, et al., Functional roles of Akt signaling in mouse skin tumorigenesis. Oncogene (2002) 21:53-64. doi:10.1038/sj.onc.1205032

109. Segrelles C, Lu J, Hammann B, Santos M, Moral M, Cascallana JL, et al., Deregulated activity of Akt in epithelial basal cells induces spontaneous tumors and heightened sensitivity to skin carcinogenesis. Cancer Res (2007) 67:10879-88. doi:10.1158/0008-5472.CAN-07-2564

110. Iwanaga K, Yang Y, Raso MG, Ma L, Hanna AE, Thilaganathan N, et al., Pten inactivation accelerates oncogenic K-ras-initiated tumorigenesis in a mouse model of lung cancer. Cancer Res (2008) 68:1119-27. doi:10.1158/0008-5472. CAN-07-3117

111. Narlik-Grassow M, Blanco-Aparicio C, Cecilia Y, Peregrina S, Garcia-Serelde B, Munoz-Galvan S, et al., The essential role of PIM kinases in sarcoma growth and bone invasion. Carcinogenesis (2012) 33:1479-86. doi:10.1093/carcin/bgs176

112. Narlik-Grassow M, Blanco-Aparicio C, Cecilia Y, Perez M, Munoz-Galvan $\mathrm{S}$, Canamero $\mathrm{M}$, et al., Conditional transgenic expression of PIM1 kinase in prostate induces inflammation-dependent neoplasia. PLoS One (2013) 8:e60277. doi:10.1371/journal.pone.0060277

113. Narlik-Grassow M, Aparicio CB, Cecilia Y, Perez M, Galvan SM, Canamero $\mathrm{M}$, et al., Piml kinase cooperates with hormone treatment to promote bladder and ureteral urothelial hyperplasia. J Carcinog Mutagen (2014) 5:161. doi:10.4172/2157-2518.1000161

114. Mulholland DJ, Tran LM, LiY, Cai H, Morim A, Wang S, et al., Cell autonomous role of PTEN in regulating castration-resistant prostate cancer growth. Cancer Cell (2011) 19:792-804. doi:10.1016/j.ccr.2011.05.006

115. Gao H, Ouyang X, Banach-Petrosky WA, Shen MM, Abate-Shen C. Emergence of androgen independence at early stages of prostate cancer progression in Nkx3.1; Pten mice. Cancer Res (2006) 66:7929-33. doi:10.1158/0008-5472. CAN-06-1637

116. Shioi T, Kang PM, Douglas PS, Hampe J, Yballe CM, Lawitts J, et al., The conserved phosphoinositide 3-kinase pathway determines heart size in mice. EMBO J (2000) 19:2537-48. doi:10.1093/emboj/19.11.2537

117. Jimenez C, Jones DR, Rodriguez-Viciana P, Gonzalez-Garcia A, Leonardo E, Wennstrom $S$, et al., Identification and characterization of a new oncogene derived from the regulatory subunit of phosphoinositide 3-kinase. EMBO J (1998) 17:743-53. doi:10.1093/emboj/17.3.743

118. Renner O, Fominaya J, Alonso S, Blanco-Aparicio C, Leal JF, Carnero A. Mst1, RanBP2 and eIF4G are new markers for in vivo PI3K activation in murine and human prostate. Carcinogenesis (2007) 28:1418-25. doi:10.1093/carcin/ bgm059

119. Renner O, Blanco-Aparicio C, Grassow M, Canamero M, Leal JF, Carnero A. Activation of phosphatidylinositol 3-kinase by membrane localization of p110alpha predisposes mammary glands to neoplastic transformation. Cancer Res (2008) 68:9643-53. doi:10.1158/0008-5472.CAN-08-1539

120. Adams JR, Xu K, Liu JC, Agamez NM, Loch AJ, Wong RG, et al., Cooperation between Pik3ca and p53 mutations in mouse mammary tumor formation. Cancer Res (2011) 71:2706-17. doi:10.1158/0008-5472.CAN-10-0738

121. Kennedy AL, Morton JP, Manoharan I, Nelson DM, Jamieson NB, Pawlikowski JS, et al., Activation of the PIK3CA/AKT pathway suppresses senescence induced by an activated RAS oncogene to promote tumorigenesis. Mol Cell (2011) 42:36-49. doi:10.1016/j.molcel.2011.02.020

122. Meyer DS, Brinkhaus H, Muller U, Muller M, Cardiff RD, Bentires-Alj M. Luminal expression of PIK3CA mutant H1047R in the mammary gland induces heterogeneous tumors. Cancer Res (2011) 71:4344-51. doi:10.1158/0008-5472. CAN-10-3827

123. Tikoo A, Roh V, Montgomery KG, Ivetac I, Waring P, Pelzer R, et al., Physiological levels of Pik3ca(H1047R) mutation in the mouse mammary gland results in ductal hyperplasia and formation of ERalpha-positive tumors. PLoS One (2012) 7:e36924. doi:10.1371/journal.pone.0036924

124. Yuan W, Stawiski E, Janakiraman V, Chan E, Durinck S, Edgar KA, et al., Conditional activation of Pik3ca(H1047R) in a knock-in mouse model promotes mammary tumorigenesis and emergence of mutations. Oncogene (2013) 32:318-26. doi:10.1038/onc. 2012.53 
125. Klarenbeek S, van Miltenburg MH, Jonkers J. Genetically engineered mouse models of PI3K signaling in breast cancer. Mol Oncol (2013) 7:146-64. doi:10.1016/j.molonc.2013.02.003

126. Liu P, Cheng H, Santiago S, Raeder M, Zhang F, Isabella A, et al., Oncogenic PIK3CA-driven mammary tumors frequently recur via PI3K pathwaydependent and PI3K pathway-independent mechanisms. Nat Med (2011) 17:1116-20. doi:10.1038/nm.2402

127. Engelman JA, Chen L, Tan X, Crosby K, Guimaraes AR, Upadhyay R, et al., Effective use of PI3K and MEK inhibitors to treat mutant Kras G12D and PIK3CA H1047R murine lung cancers. Nat Med (2008) 14:1351-6. doi:10.1038/nm.1890

128. Meyer DS, Koren S, Leroy C, Brinkhaus H, Muller U, Klebba I, et al., Expression of PIK3CA mutant E545K in the mammary gland induces heterogeneous tumors but is less potent than mutant H1047R. Oncogenesis (2013) 2:e74. doi:10.1038/oncsis.2013.38

129. Stanger BZ, Stiles B, Lauwers GY, Bardeesy N, Mendoza M, Wang Y, et al., Pten constrains centroacinar cell expansion and malignant transformation in the pancreas. Cancer Cell (2005) 8:185-95. doi:10.1016/j.ccr.2005.07.015

130. Downward J. Targeting RAS signalling pathways in cancer therapy. Nat Rev Cancer (2003) 3:11-22. doi:10.1038/nrc969

131. Gupta S, Ramjaun AR, Haiko P, Wang Y, Warne PH, Nicke B, et al., Binding of ras to phosphoinositide 3-kinase p110alpha is required for ras-driven tumorigenesis in mice. Cell (2007) 129:957-68. doi:10.1016/j.cell.2007.03.051

132. Graupera M, Guillermet-Guibert J, Foukas LC, Phng LK, Cain RJ, Salpekar A, et al., Angiogenesis selectively requires the p110alpha isoform of PI3K to control endothelial cell migration. Nature (2008) 453:662-6. doi:10.1038/ nature06892

133. Engelman JA. Targeting PI3K signalling in cancer: opportunities, challenges and limitations. Nat Rev Cancer (2009) 9:550-62. doi:10.1038/nrc2664

134. Ackler S, Ahmad S, Tobias C, Johnson MD, Glazer RI. Delayed mammary gland involution in MMTV-AKT1 transgenic mice. Oncogene (2002) 21:198-206. doi:10.1038/sj.onc. 1205052

135. Hutchinson J, Jin J, Cardiff RD, Woodgett JR, Muller WJ. Activation of Akt (protein kinase B) in mammary epithelium provides a critical cell survival signal required for tumor progression. Mol Cell Biol (2001) 21:2203-12. doi:10.1128/MCB.21.6.2203-2212.2001

136. Schwertfeger KL, Richert MM, Anderson SM. Mammary gland involution is delayed by activated Akt in transgenic mice. Mol Endocrinol (2001) 15:867-81. doi:10.1210/mend.15.6.0663

137. Blanco-Aparicio C, Canamero M, Cecilia Y, Pequeno B, Renner O, Ferrer I, et al., Exploring the gain of function contribution of AKT to mammary tumorigenesis in mouse models. PLoS One (2010) 5:e9305. doi:10.1371/journal.pone. 0009305

138. Majumder PK, Grisanzio C, O'Connell F, Barry M, Brito JM, Xu Q, et al., A prostatic intraepithelial neoplasia-dependent p27 Kip1 checkpoint induces senescence and inhibits cell proliferation and cancer progression. Cancer Cell (2008) 14:146-55. doi:10.1016/j.ccr.2008.06.002
139. Segrelles C, Moral M, Lara MF, Ruiz S, Santos M, Leis H, et al., Molecular determinants of Akt-induced keratinocyte transformation. Oncogene (2006) 25:1174-85. doi:10.1038/sj.onc.1209155

140. Segrelles C, García-Escudero R, Garín MI, Aranda JF, Hernández P, Ariza JM, et al., Akt signalling leads to stem cell activation and promotes tumor development in epidermis. Stem Cells (2014) 32:1917-28. doi:10.1002/stem.1669

141. Majumder PK, Yeh JJ, George DJ, Febbo PG, Kum J, Xue Q, et al., Prostate intraepithelial neoplasia induced by prostate restricted Akt activation: the MPAKT model. Proc Natl Acad Sci U S A (2003) 100:7841-6. doi:10.1073/ pnas. 1232229100

142. Holland EC, Celestino J, Dai C, Schaefer L, Sawaya RE, Fuller GN. Combined activation of Ras and Akt in neural progenitors induces glioblastoma formation in mice. Nat Genet (2000) 25:55-7. doi:10.1038/75596

143. Ju X, Katiyar S, Wang C, Liu M, Jiao X, Li S, et al., Aktl governs breast cancer progression in vivo. Proc Natl Acad Sci U S A (2007) 104:7438-43. doi:10.1073/pnas.0605874104

144. Deng CX, Brodie SG. Knockout mouse models and mammary tumorigenesis. Semin Cancer Biol (2001) 11:387-94. doi:10.1006/scbi.2001.0394

145. Dunbar ME, Wysolmerski JJ. Mammary ductal and alveolar development: lesson learned from genetically manipulated mice. Microsc Res Tech (2001) 52:163-70. doi:10.1002/1097-0029(20010115)52:2<163::AID-JEMT1002>3. $0 . \mathrm{CO} ; 2-\mathrm{R}$

146. Webster MA, Hutchinson JN, Rauh MJ, Muthuswamy SK, Anton M, Tortorice CG, et al., Requirement for both Shc and phosphatidylinositol $3^{\prime}$ kinase signaling pathways in polyomavirus middle T-mediated mammary tumorigenesis. Mol Cell Biol (1998) 18:2344-59.

147. Hutchinson JN, Jin J, Cardiff RD, Woodgett JR, Muller WJ. Activation of Akt1 (PKB-alpha) can accelerate ErbB-2-mediated mammary tumorigenesis but suppresses tumor invasion. Cancer Res (2004) 64:3171-8. doi:10.1158/00085472.CAN-03-3465

Conflict of Interest Statement: The authors declare that the research was conducted in the absence of any commercial or financial relationships that could be construed as a potential conflict of interest.

Received: 21 April 2014; paper pending published: 27 May 2014; accepted: 03 September 2014; published online: 23 September 2014.

Citation: Carnero A and Paramio JM (2014) The PTEN/PI3K/AKT pathway in vivo, cancer mouse models. Front. Oncol. 4:252. doi: 10.3389/fonc.2014.00252

This article was submitted to Cancer Genetics, a section of the journal Frontiers in Oncology.

Copyright (c) 2014 Carnero and Paramio. This is an open-access article distributed under the terms of the Creative Commons Attribution License (CC BY). The use, distribution or reproduction in other forums is permitted, provided the original author(s) or licensor are credited and that the original publication in this journal is cited, in accordance with accepted academic practice. No use, distribution or reproduction is permitted which does not comply with these terms. 